\title{
O gênero proposta de redação e o ato responsivo nas temáticas redacionais do ENEM: diálogo e discurso na proposta de redação
}

DOI: http://dx.doi.org/10.21165/el.v50i2.2872

\author{
Cláudia Oliveira' \\ Camila Ludovice ${ }^{2}$ \\ Ricardo Wotckoski ${ }^{3}$
}

\section{Resumo}

O presente artigo tem como objetivo demonstrar, por meio de duas propostas de redação do Exame Nacional de Ensino Médio - ENEM, dos anos de 2011 e 2018, as relações dialógicas que se estabelecem entre as propostas e os contextos histórico, social e cultural, em momentos distintos. A pesquisa demonstrou que, embora os exames tenham uma intercorrência temporal de quase uma década, ambas se dão sob impacto relevante da internet. Todavia, a primeira ocorre sob a euforia do novo, enquanto a segunda, com forte influência da manipulação resultante do controle de dados. Sobre esses aspectos são os candidatos desafiados à reflexão e à tomada de posição a respeito do tema.

Palavras-chave: ato responsivo; gênero proposta de redação; redação do ENEM, dialogismo.

\footnotetext{
1 Universidade de Franca (UNIFRAN), Franca, São Paulo, Brasil; claoliv@hotmail.com; https://orcid.org/0000-0001-7695-1679

2 Universidade de Franca (UNIFRAN), Franca, São Paulo, Brasil; camilaludovice@gmail.com; https://orcid.org/0000-0002-5998-7597

3 Faculdade de Tecnologia (FATEC), Mococa, São Paulo, Brasil; rwotckoski@gmail.com; https://orcid.org/0000-0001-7105-9286
} 


\title{
The gender proposal of writing and the responsive act in the editorial themes of ENEM: dialogue and discourse in the proposal of writing
}

\begin{abstract}
This article aims to demonstrate, through two writing proposals of the National High School Exam - ENEM, in the years 2011 and 2018, the dialogical relationships that are established between the proposals and the historical, social, and cultural contexts, in distinct moments. The research showed that, although the exams have a temporal complication of almost a decade, both take place under the relevant impact of the Internet. However, the first occurs under the euphoria of the new, while the second, with a strong influence of the manipulation resulting from data control. On these aspects, the candidates are challenged to reflect and take a stand on the topic.
\end{abstract}

Keywords: responsive act; genre writing proposal; ENEM writing, dialogism.

\section{Introdução}

O presente trabalho tem como objetivo demonstrar, por meio de duas propostas de redação do Exame Nacional de Ensino Médio - ENEM -, dos anos de 2011 e 2018, como ocorrem as relações dialógicas entre as temáticas ora analisadas e o contexto histórico, social e cultural do Brasil em épocas distintas. Nosso objetivo será, por meio da análise das propostas, demonstrar como ocorrem diálogos constantes entre as propostas e o que ocorreu socialmente no Brasil nos anos da vigência das propostas de redação em questão. É importante, aqui, ressaltar que, no Exame Nacional do Ensino Médio (ENEM), a nota da redação possui papel crucial na composição da nota final do participante, o que impacta, de forma considerável, sua entrada na universidade pública, bem como no acesso ao apoio estudantil e financiamentos afins.

As propostas de redação do ENEM aqui estudadas têm como ponto de intersecção o enunciado, distantes no tempo e no espaço. A proposta de redação do ENEM do ano de 2011 teve como temática "Viver em rede no século XXI: os limites entre o público e o privado" época em que redes sociais como Orkut, Facebook vinham à tona e os usuários de tais redes ainda não sabiam como se posicionar em relação à exposição. Já no ano de 2018, a temática redacional do Exame se fez por meio da proposta: "Manipulação do comportamento do usuário pelo controle de dados na internet". Nesse momento, a preocupação social se volta à exposição dos dados pessoais, em meio à manipulação desses advinda dos algoritmos.

Para tanto, tomaremos as propostas em questão e discutiremos pontos em comum entre elas e o que, em seu interior, possui intrínseca relação contextual histórica e social, a partir da ideia de que todo discurso não possui ineditismo, mas possui vozes anteriores que se 
intercambiam com as vozes do autor. Como arcabouço teórico, traremos as concepções de dialogismo de Mikhail Mikhailovich Bakhtin, filósofo russo.

O cotejamento entre as propostas de redação traz à tona uma reflexão acerca de um Brasil que vivenciava, em 2011, o florir das redes sociais e, em 2018, por outro lado, preocupava-se com a exposição dos dados pessoais dos usuários da internet. Em ambos os períodos, percebe-se o problema da exposição do usuário, quer seja em redes sociais ou em quaisquer sites a que se tem acesso.

Para Bakhtin (2003a), os ingredientes do ato de formação estética devem se pautar no conteúdo, na relação com o mundo, na forma, enquanto intervenção do autor. Para ele, a verdadeira noção central da pesquisa estética não deve ser o material, deve ser a arquitetônica composicional, a construção e a estrutura da obra, como intersecção entre material, forma e enunciado. Assim, a perfeição estética se encontra na imperfeição, no inacabamento do sentido. Como postulada por ele, a ideia de dialogismo nos leva à reflexão de que os enunciados permeiam discursos entre si, já que, ainda que distantes no tempo e no espaço, os diálogos sociais são irrepetíveis, mas não são inéditos. Nesse contexto, embora haja diferenças nas propostas analisadas, visto que os ideários acerca da internet são distintos, em função do tempo e do espaço, muito se encontra de congruência quando colocadas em análise, frente às preocupações sociais e em relação ao tempo-espaço.

A hipótese presente é a de que se vivenciam momentos sociais com aspectos distintos, mas que se complementam sob a égide da manipulação advinda da internet. $\mathrm{O}$ direito ao acesso à rede, a mudança de hábitos do então usuário da televisão, o perigo de arruinar reputações e a monitoração constante, presentes em "Viver em rede no século XXI...", se fazem repetir em "Manipulação do comportamento do usuário...", a partir da abordagem do traçado de retratos automatizados do gosto dos usuários de internet, do rastreamento do banco de dados, da complacência com o gosto do consumidor e das decisões feitas ao homem pela máquina. Assim, faz-se um convite à reflexão do lugar da internet na sociedade e das consequências que o uso inadequado dessa pode trazer.

Percebe-se, portanto, um dialogismo entre as propostas compostas em um interregno temporal de sete anos, que configura a presença da onipresença da manipulação do usuário da internet em quase todas as instâncias da vida social do cidadão, quer seja por meio da exposição indiscriminada nas redes sociais, quer seja pelo despreparo do usuário em expor dados e não perceber a obediência informada da qual passa a fazer parte. Nesse contexto, será privilegiada a busca pela presença do dialogismo, criada pelo filósofo russo Mikhail Bakhtin, dentro do instituto do estudo da linguagem. 


\section{Bakhtin e o dialogismo}

O filósofo russo Bakhtin, em sua concepção de dialogismo, nos traz a ideia de que a presença de dois enunciados, ainda que distantes no tempo e no espaço, quando com aspectos congruentes entre si, trazem consigo relações dialógicas que demonstram, ao menos, uma identidade ou um ponto de vista em comum. Para ele:

Qualquer resenha da história de alguma questão científica (independente ou incluída no trabalho científico sobre uma determinada questão) realiza confrontos dialógicos (entre enunciados, opiniões, pontos de vista) entre enunciados de cientistas que não sabiam nem podiam saber nada uns sobre os outros. (BAKHTIN, 2006, p. 331).

Desse modo, o aspecto em comum dos temas gera questões dialógicas. São, portanto, os enunciados aquilo que o enunciador produz com consciência, uma vez que o processo de enunciação se constitui por meio de vozes sociais. Quando um enunciado se encerra, não há acabamento, frente à presença de respostas e réplicas. Nesse ínterim, as propostas de redação ora analisadas se fazem constituir por meio de vozes sociais, produzidas por seus autores e ecoadas quando repetidas e vivenciadas por seus interlocutores, manifestando-se, portanto, no embate com a palavra do outro.

Sobre a palavra do outro, Bakhtin (2006, p. 379) afirma que:

Por palavra do outro enunciado, produção de discurso, eu entendo qualquer palavra de qualquer outra pessoa, dita ou escrita na minha própria língua ou em qualquer outra língua, ou seja, qualquer outra palavra não minha. Neste sentido, todas as palavras (enunciados, produções de discurso e literárias), além das minhas próprias, são palavras do outro.

É, para Bakhtin, trabalho do crítico o recolhimento dos dados materiais para a reconstituição do contexto histórico e a explicação deste por meio das leis sociológicas, psicológicas e biológicas, tendo a interpretação como diálogo. Assim, ao analisarmos enunciados, buscaremos vozes sociais que se cruzam e intercambiam em uma cadeia repleta de réplicas e tréplicas, localizando pontos de natureza sociológica, biológica e psicológica. É, portanto, a relação dialógica uma réplica social. Nessa instância, tanto no enunciado, como no discurso, há a constituição dialógica do dizer, conforme preconiza Bakhtin (2006, p. 199):

Em toda parte, há certa intersecção, consonância ou intermitência de réplicas do diálogo aberto com réplicas do diálogo interior das personagens. Em toda parte, certo conjunto de ideias, pensamentos e palavras se realiza em várias vozes desconexas, ecoando a seu modo em cada uma delas. 
Destarte, tem-se como balizamento das ideias do filósofo russo que o discurso do outro influencia de dentro para fora o discurso do autor, que se reflete no discurso e the dá tom e significado externo, nascendo, assim, o sentido a partir do encontro de sujeitos. Para ele, o diálogo é forma composicional do discurso, uma concepção estreita do dialogismo. Aquilo que se profere vem do outro, não vem da gramática ou das gramáticas. É a consciência, portanto, um jogo de vozes, de valores que presidem a organização do discurso, dado pelo outro. Compreender significa avaliar.

Os enunciados proferidos evidenciam relações dialógicas constantes, mesmo que estejam separados um do outro no espaço e no tempo. Isso é decorrente do que Bakhtin denomina como consciência plural, plurivocal, heteroglóssica. Assim:

Não pode haver enunciado isolado. Ele sempre pressupõe enunciados que o antecedem e o sucedem. Nenhum enunciado pode ser o primeiro ou o último. Ele é apenas o elo na cadeia e fora dessa cadeia não pode ser estudado. Entre os enunciados existem relações que não podem ser definidas em categorias nem mecânicas nem linguísticas. Eles não têm analogias consigo. (BAKHTIN, 2006, p. 371).

Percebe-se, portanto, que não ocorre isolamento em nenhum momento em relação ao enunciado, uma vez que esse faz parte de uma cadeia de vozes que se medeiam por meio das relações dialógicas. Sem elas, não há de se falar em tecer comparações.

\section{Análise da proposta de redação do ENEM 2011 sob uma perspectiva histórica e dialógica}

Em 24 de janeiro de 2004, foi criada a rede social Orkut, pelo engenheiro turco do Google Orkut Büyükkökten. A maioria dos usuários dessa rede se encontrava no Brasil e na Índia. Nessa ocasião, a rede social teve, no Brasil, mais de 30 milhões de usuários, ultrapassada somente pela rede social Facebook, que teve seu auge no Brasil por volta do ano de 2012 (ANDRADE, 2020).

As redes sociais trazem, em sua intenção, o objetivo de interação entre seus membros, por meio de troca de interesses, busca de eventos, trocas de informações profissionais e afins. No entanto, o que ocorre é que, sendo novidade a partir dos anos 2000, tais inserções nem sempre foram bem elaboradas pelos internautas, visto que a sociedade estava inserida em um contexto que o sociólogo polonês Zygmunt Bauman (2001, p. 13) intitula de pós-moderno:

O que está acontecendo hoje é, por assim dizer, uma redistribuição e realocação dos "poderes de derretimento" da modernidade. Primeiro, eles afetaram as 
instituições existentes, as molduras que circunscreviam o domínio das açõesescolhas possíveis, como os estamentos hereditários com sua alocação por atribuição, sem chance de apelação. Configurações, constelações, padrões de dependência e interação, tudo isso foi posto a derreter no cadinho, para ser depois novamente moldado e refeito; essa foi a fase de "quebrar a forma" na história da modernidade inerentemente transgressiva, rompedora de fronteiras e capaz de tudo desmoronar. Quanto aos indivíduos, porém - eles podem ser desculpados por ter deixado de notá-lo; passaram a ser confrontados por padrões e figurações que, ainda que "novas e aperfeiçoadas", eram tão duras e indomáveis como sempre.

Nesse contexto, tem-se como ideário que as relações sociais até então consideradas sólidas, têm sido esfaceladas em função da modernidade. A partir desse evento, entendese, portanto, que a sociedade necessita da discussão acerca do conviver em rede no século que nasce, o século XXI, o que deixa claro que a proposta de redação do ENEM tem como objetivo discutir a necessidade de a sociedade volver seu olhar para a questão da privacidade e perceber a força centrífuga oriunda dos elementos de manipulação social.

É neste marco que se configura a presença da normatização das regras impostas pelo Estado, por intermédio da Lei 12.965, de 23 de abril de 2014, conhecida como Marco Civil da Internet, que traz à tona questões de ajustes em relação à privacidade, como os abaixo elencados:

Art. $3^{\circ} \mathrm{A}$ disciplina do uso da internet no Brasil tem os seguintes princípios:

I - garantia da liberdade de expressão, comunicação e manifestação de pensamento, nos termos da Constituição Federal;

II - proteção da privacidade;

III - proteção dos dados pessoais, na forma da lei;

IV - preservação e garantia da neutralidade de rede;

$\checkmark$ - preservação da estabilidade, segurança e funcionalidade da rede, por meio de medidas técnicas compatíveis com os padrões internacionais e pelo estímulo ao uso de boas práticas;

VI - responsabilização dos agentes de acordo com suas atividades, nos termos da lei;

VII - preservação da natureza participativa da rede;

VIII - liberdade dos modelos de negócios promovidos na internet, desde que não conflitem com os demais princípios estabelecidos nesta Lei.

Assim, compreende-se que a Lei, que tem como objetivo primaz cuidar da privacidade do cidadão, embora traga tal proteção de forma eficaz, garantida em seus artigos, chega tarde ao país, vez que as questões de privacidade já vinham sendo discutidas pelo corpo social, bem como na proposta de redação do Exame Nacional do Ensino Médio, três anos antes de sua implementação. 
Nesse contexto, buscamos analisar o conteúdo do tema e da coletânea, denominada pela banca do ENEM como "textos motivadores", a fim de buscarmos quais os diálogos possíveis entre o que se propõe ao candidato e a realidade social do país à época da construção do tema. Além disso, há de se ressaltar como as ideologias governamentais da época se fazem presentes, ainda que implicitadas, na construção dos temas do Exame Nacional do Ensino Médio. Para tanto, iniciaremos nossa análise com o tema proposto: "Viver em rede no século XXI: os limites entre o público e o privado".

Na proposta de redação, observa-se, aqui, uma afirmação: a de que os brasileiros, no ano da proposta, 2011, já vivem em rede e que os limites entre o postado e o que deve ser resguardado devem existir. Se tais limites devem existir, ainda que implícito, fica claro na proposta que há perigo ao usuário das redes.

Importante salientar que, para que a temática da prova em discussão se entenda por completa, a fim de abarcar todas as exigências da banca, é necessário que haja:

a) Seleção, organização e interpretação de fatos, opiniões e argumentos mobilizados em defesa de um ponto de vista;

b) Elaboração de proposta de intervenção relacionada ao tema.

Infere-se, portanto, que na elaboração do tema da redação do Exame Nacional do Ensino Médio há um convite ao candidato para pensar não somente o assunto, mas uma articulação que envolva todo o cerne temático. Além disso, há a cobrança de uma solução que atenda à problemática evidenciada pelo autor do texto, com vistas ao tema, o que o exame chama de proposta de intervenção.

Nos textos motivadores da proposta de redação do ENEM do ano de 2011, há a presença de três elementos, abaixo elencados e analisados individualmente:

\section{Texto 1 da coletânea}

\section{Liberdade sem fio}

A ONU acaba de declarar o acesso à rede um direito fundamental do ser humano - assim como saúde, moradia e educação. No mundo todo, pessoas começam a abrir seus sinais privados de wi-fi, organizações e governos se mobilizam para expandir a rede para espaços públicos e regiões onde ela ainda não chega, com acesso livre e gratuito.

ROSA, G.; SANTOS, P. Galileu. No 240, jul. 2011 (fragmento). 
O texto 1, da coletânea da análise em questão, traz um texto do gênero notícia que aborda a questão do direito ao acesso à rede, estabelecido pela Organização das Nações Unidas (ONU), no ano de 2011, posto que, à época da prova, não era comum o compartilhamento da rede em espaços divididos e públicos.

\section{Texto 2 da coletânea}

\section{A internet tem ouvidos e memória}

Uma pesquisa da consultoria Forrester Research revela que, nos Estados Unidos, a população já passou mais tempo conectada à internet do que em frente à televisão. Os hábitos estão mudando. No Brasil, as pessoas já gastam cerca de $20 \%$ de seu tempo on-line em redes sociais. A grande maioria dos internautas (72\%, de acordo com o Ibope Mídia) pretende criar, acessar e manter um perfil na rede. "Faz parte da própria socialização do indivíduo do século XXI estar numa rede social. Não estar equivale a não ter uma identidade ou um número de telefone no passado", acredita Alessandro Barbosa Lima, CEO da e.Life, empresa de monitoração e análise de mídias.

As redes sociais são ótimas para disseminar ideias, tornar alguém popular e também arruinar reputações. Um dos maiores desafios dos usuários de internet é saber ponderar o que se publica nela. Especialistas recomendam que não se deve publicar o que não se fala em público, pois a internet é um ambiente social e, ao contrário do que se pensa, a rede não acoberta anonimato, uma vez que mesmo quem se esconde atrás de um pseudônimo pode ser rastreado e identificado. Aqueles que, por impulso, se exaltam e cometem gafes podem pagar caro.

Disponível em: http://www.terra.com.br. Acesso em: 30 jun. 2011 (adaptado)

O texto 2, também do gênero notícia, mostra a mudança de hábitos da população em relação ao abandono do uso da televisão, em busca do acesso à internet. O excerto também alerta o leitor a compreender que, em função das novas exigências sociais, em que não estar conectado equivale a não ter uma espécie de identidade social, é necessária a presença da ponderação em relação àquilo que se publica ou não, vez que a internet é um ambiente de cunho social e tudo o que está nela sendo posto é de cunho público. 
Figura 1. ENEM de 2011: tema da redação

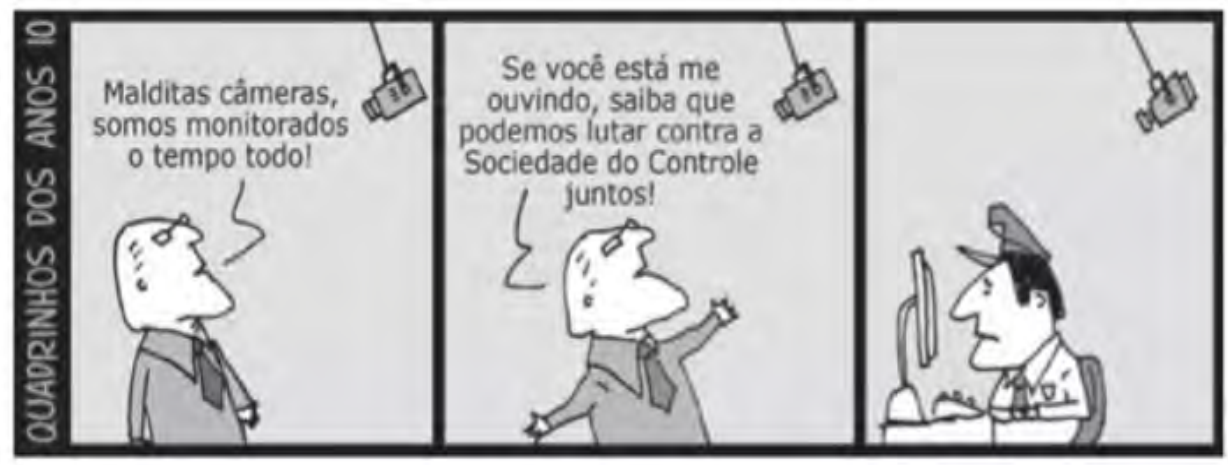

DAHMER. A Disponiver em: Hetpilimavados wordpress com. Acesso om, 30 jun 2011.

Fonte: educação.português. Disponível em: http://educacao.globo.com/portugues/assunto/ redacao/enem-2011-tema-da-redacao.html. Acesso em: 30 ago. 2020

\section{Texto 3 da coletânea}

O terceiro texto da coletânea pertence ao gênero tirinha e nele consta a ideia de que aquele que monitora também está sendo monitorado, vez que não se sabe quem vigia quem. Para Koch (2018, p. 44):

Além dos conhecimentos descritos, a escrita demanda ativação de modelos cognitivos que o produtor possui sobre práticas interacionais diversas, histórica e culturalmente constituídas. É, portanto, baseado em conhecimentos interacionais que o produtor configura na escrita a sua intenção, possibilitando ao leitor reconhecer o objetivo ou propósito pretendido no quadro interacional desenhado.

Assim, tem-se que o leitor da coletânea da proposta de redação do ENEM, a saber, o candidato, ao se defrontar com os textos motivadores, terá acionado seus conhecimentos prévios, tanto no que diz respeito ao direito universal à rede, estipulado pela ONU, como pela advertência ao cuidado que se tem de tomar ao expor comentários e afins na internet, em função da constante vigilância. Isso traz à tona as ideias de Bakhtin, já que aqui evidencia-se um diálogo constante entre o tema da redação, que aborda uma preocupação social dos anos 2010 vinculada a um novo fenômeno social, que é a troca da audiência da televisão pela internet.

Tem-se, portanto, nos textos motivadores um balanceamento entre o que o produtor da coletânea traz ao leitor da prova e o conhecimento interacional desse, o que se dá por meio de um diálogo, mediado pela condição social da época da produção do texto, conforme preconizam as ideias bakhtinianas. 


\section{Análise da proposta de redação do ENEM 2011 sob uma perspectiva histórica e dialógica}

No ano de 2018, a proposta de redação do Exame Nacional do Ensino Médio teve como tema "A manipulação do controle de dados do usuário pela internet". Essa temática torna possível analisar quais pontos de vista há em comum com o tema de redação do ano de 2011, bem como quais as diferenças relacionadas ao conteúdo da proposta, sob o ponto de vista dialógico. Assim, tem-se na proposta de redação os seguintes textos de apoio:

\section{TEXTO I}

Às segundas-feiras pela manhã, os usuários de um serviço de música digital recebem uma lista personalizada de músicas que Ihes permite descobrir novidades. Assim como os sistemas de outros aplicativos e redes sociais, este cérebro artificial consegue traçar um retrato automatizado do gosto de seus assinantes e constrói uma máquina de sugestões que não costuma falhar. 0 sistema se baseia em um algoritmo cuja evolução e usos aplicados ao consumo cultural são infinitos. De fato, plataformas de transmissão de vídeo começam a desenhar suas séries de sucesso, rastreando banco de dados gerado por todos os movimentos dos usuários para analisar o que os satisfaz. O algoritmo constrói assim um universo cultural adequado e complacente com o gosto do consumidor, que pode avançar até chegar sempre a lugares reconhecíveis. Dessa forma, a filtragem de informação feita pelas redes sociais ou pelos sistemas de busca pode moldar nossa maneira de pensar. E esse é o problema principal: a ilusão de liberdade de escolha que muitas vezes é gerada pelos algoritmos.

VERDÚ, Daniel. O gosto na era do algoritmo. Disponível em: https://brasil.elpais. com. Acesso em: 11 jun. 2018 (adaptado)

O texto 1 da coletânea traz um texto do gênero notícia, no qual trazem-se as informações de que há, por detrás das sugestões oferecidas ao internauta, uma inteligência artificial imbuída de valores predeterminados, em função da existência de algoritmos que fazem o usuário supor que está escolhendo, quando, na verdade, está sendo direcionado a escolher aquilo que as plataformas digitais sugerem. Eis a temática abordada acerca da manipulação.

Nesse contexto, tem-se o ideário de que as necessidades individuais, embora tidas como do cidadão, não são dele, vez que é a indústria cultural que dita os valores, conforme preconiza Adorno (1986, p. 70):

Se a organização da sociedade impede, de um modo automático ou planejado, pela indústria cultural e da consciência e pelos monopólios de opinião, o conhecimento e a experiência dos mais ameaçadores eventos e das ideias e teoremas críticos 
essenciais; se, muito além disso ela paralisa a simples capacidade de imaginar concretamente o mundo de um modo diverso de como ele dominadoramente se apresenta àqueles pelos quais ele é construído, então o estado de espírito fixado e manipulado torna-se um poder real - um poder de repressão - quanto outrora o oposto da repressão, o espírito livre, quis eliminá-la.

Assim, tem-se que os monopólios de opinião são agentes manipuladores e detentores de um poder que reprime o pensamento livre e a livre escolha. Atrelando as ideias do pensador ao primeiro texto de apoio da proposta de redação ora analisada, evidencia-se que além da escolha predeterminada ao usuário da internet, ainda há a preponderância da indústria cultural, que aliena o espírito livre do cidadão e lhe tira o poder de escolha.

\section{TEXTO II}

Nos sistemas dos gigantes da internet, a filtragem de dados é transferida para um exército de moderadores em empresas localizadas do Oriente Médio ao Sul da Ásia, que têm um papel importante no controle daquilo que deve ser eliminado da rede social, a partir de sinalizações dos usuários. Mas a informação é então processada por um algoritmo, que tem a decisão final. Os algoritmos são literais. Em poucas palavras, são uma opinião embrulhada em código. E estamos caminhando para um estágio em que é a máquina que decide qual notícia deve ou não ser lida.

PEPE ESCOBAR. A silenciosa ditadura do algoritmo. Disponível em: http:// outraspalavras.net. Acesso em: 5 jun. 2017 (adaptado).

O texto II da coletânea da prova de redação do ENEM, do gênero dissertativo-argumentativo, traz os fatos acerca da filtragem de dados e como isso ocorre em termos logísticos. Dessa forma, demonstra ao leitor que aquilo que deve ou não ser lido é definido por um sistema de algoritmos. Assim, ao final do texto, ocorre a argumentação, por parte do autor, de que a máquina decide o que estamos lendo ou não.

Sabe-se que, muito antes do surgimento do Estado, decisões e conflitos se resolviam por intermédio da autotutela, em que se vigia o aforismo da lei do mais forte. Com o advento da organização social corporificada pelo Estado, passou-se da esfera privada para a esfera pública, em que o Estado, suficientemente fortalecido impõe-se sobre os particulares e prescinde da voluntária submissão desses por meio da autoridade. No entanto, tanto as decisões estatais, como as individuais perderam força frente às decisões do cidadão após o advento dessa nova forma de manipulação, em que uma terceira voz "dialoga" com o usuário da internet, fazendo-o pensar que as escolhas são dele. Assim, fatores históricos e culturais arraigados são postos de lado, abandonandose todo o idealismo social, em função de imposições midiáticas de interesse que fazem as escolhas do internauta, o que cria um novo fenômeno social, confirmado pelo gráfico que segue no texto III: 
Figura 2. Tema de redação ENEM 2018: Manipulação do comportamento do usuário pelo controle de dados na internet

\section{TEXTO III}

\section{Utilização da Internet}

$64,7 \%$ das pessoas de10 anos ou mais de idade utilizaram a Internet.

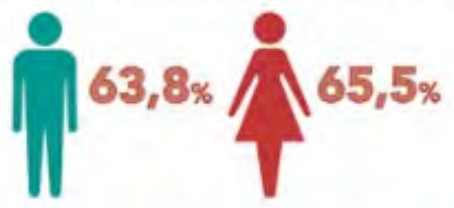

Cerca de $85 \%$ dos jovens de 18 a 24 anos de idade e $25 \%$ das pessoas de 60 anos ou mais de idade utilizaram a Internet.

Cerca de $\mathbf{7 5} \%$ das pessoas de 10 anos ou mais de idade que não acessaram a Internet, nāo o fizeram por nâo saberem usá-la ou por falta de interesse.

\section{Finalidade do acesso à Internet (\%)}

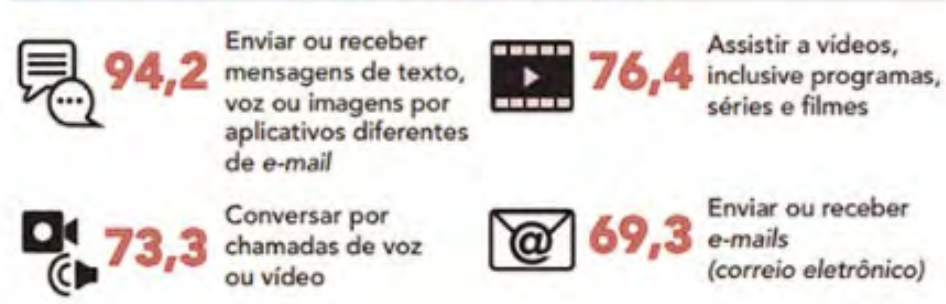

Internet no Brasil em 2016. Disponível em: www.ibge.gov.br. Acesso em: 18 jun. 2018 (adaptado).

Fonte: Imaginie. Disponível em: https://www.imaginie.com.br/temas/tema-de-redacaoenem-2018/. Acesso em: 30 ago. 2020.

O terceiro texto da coletânea, do gênero gráfico, demonstra o número de pessoas conectadas à internet, trazendo os seguintes dados:

a) Há um número considerável de pessoas (64,7\%) com mais de 10 anos que faz uso da internet;

b) $75 \%$ dessa faixa etária que não usa a internet não o faz por desconhecimento ou desejo próprio;

c) Há praticamente igualdade de acesso entre os gêneros (63,8\% homens e $65,5 \%$ mulheres) em relação ao uso da internet; 
d) Dentre essas pessoas, aquelas com 18 a 24 anos que utilizaram a rede compõem $85 \%$;

e) $25 \%$ desse grupo é composto por jovens;

f) A internet é utilizada, majoritariamente, para o envio ou recebimento de mensagens diversas (94,2\%), assistir a vídeos diversos (76,4\%), conversar por chamadas $(73,3 \%)$ e 69,3\% para enviar e receber e-mails.

Tem-se, portanto, por meio do gênero gráfico, um indicativo informativo que traz o ideário de que há uma gama considerável de pessoas, de todas as faixas etárias, que faz uso da internet, para fins diversos, o que nos faz chegar à conclusão de que, na atualidade, a presença desse meio de comunicação se tornou imprescindível. Nesse contexto, o texto IV, da coletânea, demonstra como essa exposição à internet se torna alvo fácil para a manipulação e, por conseguinte, para o controle de dados:

\section{TEXTO IV}

Mudanças sutis nas informações às quais somos expostos podem transformar nosso comportamento. As redes têm selecionado as notícias sob títulos chamativos como "trending topics" ou critérios como "relevância". Mas nós praticamente não sabemos como isso tudo é filtrado. Quanto mais informações relevantes tivermos nas pontas dos dedos, melhor equipados estamos para tomar decisões. No entanto, surgem algumas tensões fundamentais: entre a conveniência e a deliberação; entre o que o usuário deseja e o que é melhor para ele; entre a transparência e o lado comercial. Quanto mais os sistemas souberem sobre você em comparação ao que você sabe sobre eles, há mais riscos de suas escolhas se tornarem apenas uma série de reações a "cutucadas" invisíveis. O que está em jogo não é tanto a questão "homem versus máquina", mas sim a disputa "decisão informada versus obediência influenciada".

CHATFIELD, Tom. Como a internet influencia secretamente nossas escolhas. Disponível em: www.bbc.com. Acesso em: 3 jun. 2017 (adaptado).

Tem-se, nessa esfera, um texto de cunho dissertativo-argumentativo, com informações relevantes de como os filtros de escolha são elaborados e como as escolhas individuais da sociedade atual são postas em risco, em meio a questões éticas que estão sendo deixadas de lado, frente a esse novo fenômeno social.

Nesse contexto, as temáticas de redação propostas nos anos de 2011 e 2018 possuem relações intercambiáveis de diálogo, em que há a presença de pontos convergentes e divergentes. 


\section{O dialogismo entre os temas de redação do ENEM}

De acordo com a análise ora apresentada, temos como pressuposto a ideia advinda do filósofo russo Mikhail Bakhtin de que as relações dialógicas permeiam a vida, ainda que textos distintos estejam em locais e tempos distintos. Assim, por meio do discurso dialógico, buscamos compreender como as temáticas redacionais do Exame Nacional do Ensino Médio dialogam entre si, ao encontro das necessidades atuais da sociedade, à época em que foram produzidas.

Nesse contexto, é importante ressaltar como os temas das redações em análise permitem que o discurso que traz as necessidades sociais emerja e seja aceito pela sociedade contemporânea. Para isso, buscaremos entender como o tema "Viver em rede no século XXI: os limites entre o público e privado", produzido em 2011, serve de palco para o que foi aplicado no ano de 2018. Assim, a abordagem da primeira temática em relação à internet passou por alterações. O primeiro fragmento da coletânea do ano de 2011 é uma publicação da revista Galileu, do mesmo ano. Nesse excerto, o acesso à rede, livre e gratuito, é anunciado como um novo direito humano. Já na proposta do ano de 2018, aquilo que seria um direito fundamental sete anos antes torna-se um problema, o que é demonstrado por um fragmento, cujo título é "O gosto na era do algoritmo", de publicação do mesmo ano, no site "brasil.elpais". Nesse fragmento, há a abordagem de que os gostos dos usuários da internet são traçados e direcionados, por meio da filtragem de informações, a escolhas que, supostamente, dão ao usuário a liberdade de escolha, mas, que verdadeiramente, levam-no à manipulação por meio do controle de dados. Mesmo com divergências nesse sentido, as congruências são evidentes, vez que, apesar de as propostas terem enfoques diferentes, a crítica se faz bastante parecida. Em 2011, embora se mostre o direito à rede, tem-se na proposta a necessidade de se ter limites entre o que se publica ou não. Em 2018, mostra-se a consequência da inadequação das publicações, visto que aquilo que se torna público, torna-se manipulável.

É nesse ponto que os aspectos congruentes se tornam claros e as relações dialógicas se fazem presentes. Nessa perspectiva, enquanto efeitos da alteridade, buscamos a manifestação da linguagem como uma das vertentes do processo composicional, seja por meio da ironia, seja por meio da crítica direta ou velada, sob um viés histórico e social, a partir de uma confluência de discursos, que forma um tabuleiro social, merecedor de uma análise do contexto de produção do enunciado. Pode-se inferir, a partir de tal assertiva, que os discursos, não isentos de responsabilidade, que abarcam fatores contextuais históricos, são passíveis de controle e vigilância, e de censura social, por serem formas de contestação de valores preestabelecidos socialmente ou impostos por instituições que regem ad eternum as sociedades, justamente por estarem situados em determinado tempo e espaço, o que Ihes delimita questões histórico-ideológicas.

A inspiração para a primeira proposta analisada veio do fenômeno das redes sociais, que se intensificou no ano de 2011, momento em que a rede "Orkut" se consolidou e dava 
voz à nova rede que se intensificou, a partir desse ano, o "Facebook". Além da crítica à exagerada postagem daquilo que é privado, há de se ressaltar a questão da perda de liberdade, à luz daquilo que é explicitado no segundo texto da coletânea do ano de 2011, que mostra, por meio de uma publicação no site Terra, a necessidade de se ponderar aquilo que é publicado em redes sociais, posto que o que o que é levado em conta é a mudança de hábitos pela qual passou o brasileiro, que outrora passava o tempo em frente à televisão. Desse modo, percebe-se, nesse diálogo, com a proposta de 2018 que os temores se consolidaram, a partir da contemplação do explicitado no texto 2, da coletânea da proposta do ano de 2018 de que a filtragem de dados já é uma realidade e define aquilo que o usuário da internet lê ou não.

Embora as propostas tenham sido produzidas em épocas díspares, a ideologia prevalece. Nesse âmbito, os cronotopos se alternam, mas o discurso se mantém e aborda, com precisão habitual, a temática existente entre ambos, a partir da instauração de um diálogo entre cidadão e polícia.

Há ainda de se dissecar as outras várias relações dialógicas, quando na apresentação das propostas. O Texto 3, apresentado no ano de 2011, traz um texto do gênero "tira", de A. Dahmer, extraído do site malvados.wordpress.com, que remonta à frase "Quem vigia o vigia que vigia quem te vigia?", exposta no documentário acerca do livro 19844, de George Orwell dialoga, de forma direta, com o exposto na proposta de redação do ano de 2018, que trata, claramente, do controle e vigilância do internauta. Ainda nesse âmbito, no que concerne à manipulação e controle, a proposta de 2018 traz, no texto final de apoio, a questão da quantidade de informações que os sistemas têm sobre o usuário, em relação à quantidade de informações que o usuário tem sobre o sistema. Tal excerto foi extraído do site da BBC, e tem como título "Como a internet influencia secretamente nossas escolhas", de Tom Chatfield.

Eis que nos fragmentos acima emergem o desejo e a necessidade de proteção, bem como a consciência de que esses não serão efetivos, em função da supremacia da internet em relação ao cidadão comum.

Esse indivíduo, em nome da coletividade se vê imposto pelos códigos sociais de imposição e submissão. São códigos que dialogam com outros códigos, como a presença da força, quer seja do Estado, da Igreja, da Escola, da Família ou da Mídia, representada pela internet, que surgem e ressurgem a qualquer momento e se reforçam em tempos e locais distintos, irrepetíveis, no entanto, com algo em comum, não inédito.

4 Livro publicado em 1949, pelo britânico George Orwell, que trata de uma distopia frente à imposição de um líder, "Grande Irmão", em uma sociedade que se submete à opressão, por meio de constante vigia. 
Assim, com os elementos extraídos dos textos de apoio das propostas de redação do Exame Nacional do Ensino Médio, tem-se clara a incapacidade do representante da instituição estatal em enxergar a fragilidade do cidadão comum, enquanto a internet se faz detentora do poder oriundo de outras instituições basilares.

Entendemos, portanto, que enunciados congruentes, ainda que distantes na questão tempo-espacial possuem relações intrínsecas entre si, relações dialógicas, uma vez que cada tempo e espaço trazem consigo marcas históricas e ideológicas que podem intercambiar entre si. O posicionamento e a confrontação ético-axiológicos medeiam os discursos. As conviç̧ões dos participantes do diálogo são determinadas pela sua leitura de mundo.

Torna-se essencial afirmar que os enunciados são produzidos sem consciência pelo enunciador, que os faz por meio de vozes sociais. Quando um enunciado se encerra, não há acabamento, com a presença de respostas e réplicas. Os motivos espaço-temporais ensejam a presença de tais réplicas e tréplicas.

Assim, em ambas as propostas, encontra-se a voz do corpo social presente na voz do autor. Em um contexto atual de pós-modernidade, ocorre, portanto, um conflito que torna as instituições de cerceamento comportamental esfaceladas e tendentes às múltiplas formas de rejeição. O sujeito, diante de restrições sociais, traz consigo modos de se manter no usufruto que lhe permite viver e conviver socialmente, mas se depara, justamente, com a força oculta da internet, o que lhe traz a manipulação. Essas nuances são percebidas em ambas as propostas aqui discutidas.

Assim, têm-se as relações dialógicas presentes nos textos que demonstram o processo de reificação do cidadão, em busca de uma voz ativa em um processo que justamente Ihe oferece o contrário. Dessa forma, é relevante que se busque abrir a discussão acerca das imposições advindas, uma vez que se ouve falar aleatoriamente sobre a temática proposta sem que se abram discussões relevantes.

Daí a primazia evidenciada em "Viver em rede no século XXI: os limites entre o público e o privado" e "Manipulação do comportamento pelo controle de dados na internet", separadas pelo interregno temporal de sete anos, mas que buscam, em comum, a presença marcante da submissão do indivíduo ao meio cultural e ideológico que o cerca.

É importante frisar que diante das premissas falidas do modelo institucional de força e proteção ao cidadão, bem como a fragilização da imagem paternal do Estado e da descrença nesse, o cidadão não encontra mais barreiras fortes o suficiente para protegêlo, o que, por conseguinte, gera nele a necessidade de arcar com a quebra da tensão pulsional que o conduz. 
Por fim, cabe salientar que a relevância dos textos de apoio aqui demonstrados contribuiu, em muito, para o pensamento acerca dos parâmetros culturais e ideológicos e de cunho perceptivo dos papéis do corpo social. São excertos que advêm de textos inovadores que se contrapõem ao pensamento de aceitação e submissão, em busca de individualidade e convicção.

\section{Considerações finais}

Nosso estudo desenvolveu-se a partir das reflexões sobre as relações dialógicas entre as propostas de redação do Exame Nacional do Ensino Médio dos anos de 2011 e 2018, por meio das contribuições do filósofo russo Mikhail Bakhtin.

Embora haja um interregno temporal entre a composição das propostas em questão, buscamos analisar o que ambas traziam em comum em relação ao pensamento citadino e às questões sociais e históricas em ambos os períodos.

Obtivemos, portanto, a verificação de que, passada quase uma década, as forças impositivas advindas da internet se fazem presentes, ainda que a população a ela reaja de forma diversa, vez que, em uma primeira análise, há a presença da novidade frente ao novo, trazido pelas redes sociais e, no segundo, jaz a força da imposição manipulativa por meio do controle de dados.

Portanto, em um Estado civilizatório, o cidadão, dito comum, embora ceda seus desejos ao aparato social, não só se faz presente não como um ser alienado e que aceita as imposições vindas das instituições, mas aceita as forças impostas por elas, aspecto extremamente relevante e presente nas propostas analisadas. Tal assertiva ganha mais contornos a partir do momento em que as propostas se popularizam e tendem, ainda que inconscientemente, a levar o citadino à reflexão acerca da temática e quiçá, ao afastamento das forças impostas pelas instituições, sejam elas quais forem.

\section{REFERÊNCIAS}

ADORNO, T. W. Sociologia. Organização de Gabriel Cohn. São Paulo: Ática, 1986.

ANDRADE, G. O que é Orkut. Disponível em: https://www.infoescola.com/informatica/oque-e-orkut/.Acesso em: 30 set. 2020.

BAKHTIN, M. Estética da criação verbal. Tradução Paulo Bezerra. 4. ed. São Paulo: Martins Fontes, 2006. 
BAKHTIN, M. O problema do autor. In: BAKHTIN, M. Estética da criação verbal. 4. ed. São Paulo: Martins Fontes, 2003a. p. 173-192.

BAKHTIN, M. Os gêneros do discurso. In: BAKHTIN, M. Estética da criação verbal. 4. ed. São Paulo: Martins Fontes, 2003b. p. 261-306.

BAUMAN, Z. Modernidade Líquida. 4. ed. Rio de Janeiro: Jorge Zahar, 2001.

KOCH, I. G. V.; ELIAS, V. M. Ler e escrever: estratégias de produção textual. 2. ed. São Paulo: Contexto, 2014. 